\title{
Marriage: Direct and continuous measurement
}

\author{
DIANE DeA. EDWARDS and JOSEPH S. EDWARDS \\ University of Missouri, Kansas City, Missouri 64110
}

\begin{abstract}
Marriage partners who were college students were asked to count and chart the frequency of marital behaviors (sexual intercourse, arguments, and socials) per day for a period of at least 3 months. Functional relationships were found between arguments and sex. Couples who engaged in sexual intercourse at a higher rate than they argued described their marriage as "happy." Marriages with rates of argument higher than rates of intercourse described their relationship as "definitely unhappy." Daily records of these behaviors functionally pinpointed and quantified changes in the status of a couple's marriage across time. In marriages described as "tolerable," the sex rate was only slightly higher than the rate of arguments, but both rates were extremely low.
\end{abstract}

Questionnaires are most commonly used in marriage research. Hamilton (1929) was among the first to design a scale which sought to measure marital success. Campbell (1975) conducted one of the more recent surveys. Questionnaires and rating scales are by far the most frequently used method to obtain information about marriage. Waller and Hill (1951) highlighted inadequacies in these methods when they analyzed the number of significant findings across 20 studies. The most important finding indicated that, of these studies, five showed the happiness of the husband's parents' marriage was significantly related to the happiness of their son's marriage. Unfortunately, that was the highest agreement found. With such scant information, it is understandable why marriage partners who want to find relevant information concerning what goes on in marital relationships find themselves somewhat confused and sometimes misled. Currently, the single most important contributions to this general area of research are the specific data, relationships, and therapeutic results concerning sexual inadequacies that Masters and Johnson (1970) have published.

A review of the literature on marital research indicates that sexual intercourse and conflict (arguments) are the most important behaviors that determine marital happiness (Bach \& Wyden, 1969; Barry, 1970; Blood \& Wolfe, 1968; Davis, 1929; Dickinson \& Beam, 1931; Hamilton, 1929; Kinsey, Pomeroy, Martin, \& Gebhard, 1953; Landis \& Landis, 1963; Masters \& Johnson, 1970; Pace, 1940; Terman, 1950). Social engagements by the couple is another variable emphasized (Locke, 1951; Waller \& Hill, 1951). The extent to which a couple incorporates and engages in these behaviors is unknown. It is known, however, that when couples, individuals, and professionals are asked to predict how often they engage in a behavior (frequency), error rates range from $18 \%$ to $90 \%$ when compared with recorded behavior rates (Edwards, 1976). Interestingly, we rediscovered the behaviors listed above as potential indicators that would explicate the ongoing status of our marriage without reading the literature. We were interested in finding out about the intricacies of marriage.

\section{METHOD}

\section{Subjects}

One hundred and ten couples recorded the number of times they engaged in sexual intercourse, argued, and socially entertained in and outside their home daily over intervals of 20 to 3,650 days (median 100 days). Age of the subjects ranged from 19 to 67 years, with a median age of 28.5 years for the husband and 25 years for the wife. Duration of the marriage ranged from 6 months to 30 years and the number of children per couple varied from zero to eight. In all cases but one, one member of each couple was attending college either full or part-time during the study.

\section{Procedure}

The behaviors to be recorded were defined in the following ways: Sexual intercourse-the number of times the couple engage in intercourse. Argument-any marital interaction which produces behavioral deceleration in communication and cooperation. These decelerations most often include leaving the situation (physically or verbally), personal verbal attacks, or emotional outbursts such as crying or brooding. Socials-each time the couple interacts with one or more persons (friends, relatives, other acquaintances) not normally living in the home, whether that interaction occurs in or outside the home. The number of times each of these behaviors occurred was recorded daily and charted so that each couple could see a graphic representation of their marital relationship. Couples were also asked to characterize their marriage as happy, tolerable, or unhappy. In addition, most couples recorded environmental events such as menstruation, visits from in-laws, exams, shopping trips, and so forth, at the point on the chart when they occurred.

\section{RESULTS}

Figure 1 displays representative data from couples who reported happy (A), tolerable (B), and unhappy (C) marriages. That a functional relationship exists between sex and arguments is evident from analyzing the way these two behaviors interact across the three couples. The happy couple engages in sexual intercourse approximately three times as often as they argue. Sexual intercourse on argument days is infrequent (1 out of 6). The tolerable and unhappy marriages are charac- 


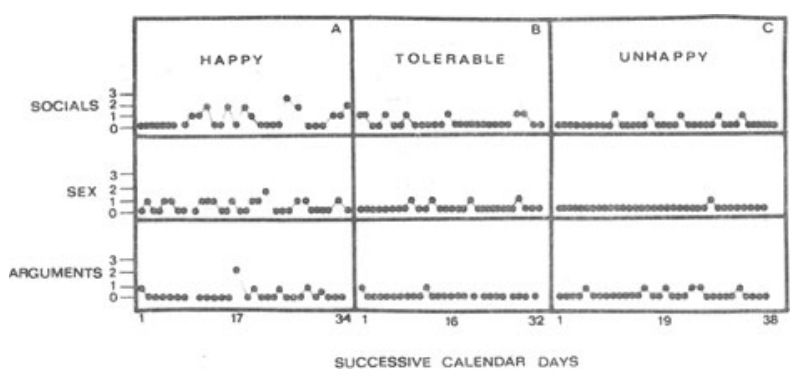

Figure 1

terized by very low rates in the three recorded behaviors. The principal distinguishing feature between the two couples is the higher sex and social rate in the "tolerable" marriage (B). This couple never engaged in sexual intercourse on days that they argued. However, in spite of the low sex rate, this couple, over the time period shown, engaged in sexual intercourse twice as often as they argued. The "unhappy" couple also never engaged in sexual intercourse on the days they argued. Arguments in this couple occurred six times more often than sex. Both members of this couple stated that it was "definitely an unhappy marriage." An analysis of arguments and socials indicated that arguments tended to occur much more frequently on nonsocial days. The unhappy couple (C) argued twice as often on nonsocial days.

An analysis of the data from the 110 couples revealed: ${ }^{1}$ (1) $54 \%$ rated their marriages as happy; only $7 \%$ of these couples argued more often than they engaged in intercourse (in each case these couples had high argument and intercourse rates), (2) $11 \%$ reported tolerable marriages; $57 \%$ argued more often than they engaged in sexual intercourse, (3) 18\% reported unhappy marriages; $100 \%$ of these couples argued more often than they engaged in sexual intercourse, and (4) $17 \%$ refused to evaluate their marriage; in $6 \%$ of these couples the argument rate was higher than the rate of intercourse.

An analysis of other variables showed that: (1) The menstrual period was characterized by a decrease in sexual intercourse and arguments, (2) the occurrence of sexual intercourse on argument and nonargument days (excluding the menstrual period) was not systematically related, and (3) in $74 \%$ of the couples, argument rates increased during "in-law" visits.

These data show that the ongoing relationship between arguments and sex is a reliable means of quantifying the dynamic status of marriages.

\section{DISCUSSION}

The method described in this paper clearly shows the advantages of direct, continuous recordings of behaviors that reflect the social interactions in marital couples. Daily records of sexual intercourse, arguments, and socials were found functionally: (1) to describe changes in the status of a couple's marriage across time, and (2) to identify and quantify periods of time when couples were happy, tolerably happy, or unhappy.

The most dramatic findings concern the relationship of rate of sex and arguments. A high rate of argument was a definite characteristic of an unhappy marriage. All unhappily married couples argued more often than they engaged in sexual intercourse. Couples who engaged in sexual intercourse more of ten than they argued described their marriage as happy. An absolute ratio of sex to arguments is not known, but the direction must favor sex in order for the couple to describe themselves as happily married.

In marriages which ended in divorce, sex decelerated to zero long before arguments (often several months prior) and then both sex and arguments reached zero rates.

This sex-argument ratio has successfully been used to provide quantified data to assess the status of marriages in trouble and to chart improvement in the marriage through marital counseling.

Again, it should be noted that direct, continuous recordings of behaviors in single couples provide more precise information about a relationship than the use of aperiodic, indirect behavioral measures (questionnaires, rating scales).

\section{REFERENCES}

BACH, G., \& Wyden, P. The intimate enemy. New York: William Monrow, 1969.

BARRY, W. A. Marriage research and conflict: An integrative review. Psychological Bulletin, 1970, 73, 41-54.

Blood, R. O., \& Wolfe, D. M. Husbands and wives. In R. R. Bell (Ed.), Studies in marriage and the family. New York: Thomas Y. Crowell, 1968.

Campbell, A. The American way of marriage. Psychology Today, 1975, 9, 37-43.

DAvis, K. B. Factors in the sex life of twenty-two hundred women. New York: Harper, 1929.

Dickinson, R. L., \& BEAM, L. A. A thousand marriages. Baltimore: Williams \& Wilkins, 1931.

EDWARDS, J. S. Words vs records: A practical behavior recording exercise for psychology courses. Teaching of Psychology, 1976, 3, 35-37.

Hamiton, G. V. A research in marriage. New York: Albert \& Charles Boni, 1929.

Kinsey, C., Pomeroy, W. B., Martin, C. E., \& Gebhard, P. H. Sexual behavior in the human female. New York: Saunders, 1953.

LANDIs, J. T., \& LANDIs, M. G. Building a successful marriage (4th ed.). New York: Prentice-Hall, 1963.

Locke, H. J. Predicting adjustment in marriage: $A$ comparison of a divorced and a happily married group. New York: Henry Holt, 1951.

Masters, W. H., \& Johnson, V. E. Human sexual inadequacy. Boston: Little, Brown, 1970.

PACE, C. R. Problems in family relationships among young married adults. Marriage and Family Living, 1940, 2, 42-43.

Terman, L. M. Prediction data. Marriage and Family Living, 1950, 12, 51-54.

WALLER, W. W., \& Hill, R. The family: A dynamic interpretation. New York: Holt, 1951.

\section{NOTE}

1. We appreciate help from Sharon Alexander and John Howard. 